\title{
Value of Neutrophil to Lymphocyte Ratio and Its Trajectory in Patients Hospitalized With Acute Heart Failure and Preserved Ejection Fraction
}

\author{
Kalyani Anil Boralkar, MD ${ }^{\mathrm{a}, 1}$, Yukari Kobayashi, MD ${ }^{\mathrm{a}, \mathrm{b}, 1}$, Myriam Amsallem, MD, PhD ${ }^{\mathrm{a}, \mathrm{b}, \mathrm{f}}$, \\ Jennifer Arthur Ataam, PhD ${ }^{\mathrm{a}, \mathrm{b}, \mathrm{c}, \mathrm{f}}$, Kegan J. Moneghetti, MBBS (hons), PhD ${ }^{\mathrm{a}, \mathrm{b}}$, \\ Nicholas Cauwenberghs, $\mathrm{PhD}^{\mathrm{d}}$, Benjamin D. Horne, PhD, MStat, MPH ${ }^{\mathrm{a}, \mathrm{e}}$, Kirk U. Knowlton, MD ${ }^{\mathrm{e}}$, \\ Holden Maecker, $\mathrm{PhD}^{\mathrm{c}}$, Tatiana Kuznetsova, $\mathrm{MD}, \mathrm{PhD}^{\mathrm{d}}$, Paul A. Heidenreich, MD, MS ${ }^{\mathrm{a}}$, and \\ Francois Haddad, MD ${ }^{\mathrm{a}, \mathrm{b}, *}$
}

\begin{abstract}
The neutrophil to lymphocyte ratio (NLR) has been proposed as a simple and routinely obtained marker of inflammation. This study sought to determine whether the NLR on admission as well as NLR trajectory would be complementary to the Get with the Guidelines Heart Failure (GWTG-HF) risk score in patients hospitalized with acute heart failure with preserved ejection fraction (HFpEF).Using the Stanford Translational Research Database, we identified 443 patients between January 2002 and December 2013 hospitalized with acute HFpEF and with complete data of NLR both on admission and at discharge. The primary endpoint was all-cause mortality. Mean age was $77 \pm 16$ years, $58 \%$ were female, with a high prevalence of diabetes mellitus $(35.4 \%)$, coronary artery disease $\mathbf{5 8 . 2 \%})$, systemic hypertension (96.6\%) and history of atrial fibrillation (57.5\%). Over a median follow-up of 2.2 years, $121(27.3 \%)$ patients died. The median NLR on admission was 6.5 (IQR 3.6 - 11.1); a majority of patients decreased their NLR during the course of hospitalization. On multivariable Cox modeling, both NLR on admission (HR 1.18 95\% CI $(1.00-.38), p=0.04)$ and absolute NLR trajectory (HR $1.2695 \%$ CI $(1.10-1.45)$, $p=0.001)$ were shown to be incremental to GWTG-HF risk score $(p<0.05)$ for outcome prediction. Adding the NLR or absolute NLR trajectory to the GWTG-HF risk score significantly improved the area under the operator-receiver curve and the reclassification up to 3 years after admission. This simple, readily available marker of inflammation may be useful when stratifying the risk of patients hospitalized with HFpEF. () 2019 Elsevier Inc. All rights reserved. (Am J Cardiol 2019;00:1-7)
\end{abstract}

Heart failure with preserved ejection fraction (HFpEF) is a major cause of morbidity and mortality. ${ }^{1-5}$ Inflammation and activation of innate immunity appear to be common in HFpEF and have been associated with poor survival. ${ }^{6-8}$ There has been a revived interest in recent years to explore the value of routinely obtained markers of inflammation for risk prediction. The neutrophil to lymphocyte ratio (NLR), a simple marker of neutrophil count normalized for the

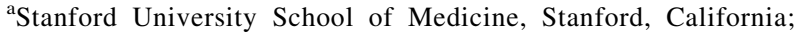
${ }^{\mathrm{b}}$ Stanford Cardiovascular Institute, Stanford, California; ${ }^{\mathrm{C}}$ Institute for Immunity, Transplantation and Infection, Stanford, California; ${ }^{\mathrm{d}}$ Department of Cardiovascular Sciences, Research Unit Hypertension and Cardiovascular Epidemiology, KU Leuven, University of Leuven, Leuven, Belgium; ${ }^{\mathrm{e}}$ Intermountain Heart Institute, Salt Lake City, Utah; and ${ }^{\mathrm{f}}$ Research and Innovation Unit, INSERM U999, DHU TORINO, Paris Sud University, Marie Lannelongue Hospital, Le Plessis Robinson, France. Manuscript received July 2, 2019; revised manuscript received and accepted October 8, 2019.

Funding: This work was supported by the Intermountain-Stanford Collaboration Initiative and the Philips Royal Research grant of heart failure with preserved ejection fraction.

${ }^{1} \mathrm{KAB}$ and $\mathrm{YK}$ contributed equally to this study.

See page 6 for disclosure information.

*Corresponding author: Tel: (650) 799-0373; fax: (650) 725-1599

E-mail address: fhaddad@stanford.edu (F. Haddad).
}

lymphocyte count, has recently gained importance as a sensitive inflammatory marker associated with poor outcomes in various cardiovascular settings. ${ }^{9,10}$ Data on the prognostic value of NLR in patients hospitalized with acute HFpEF, however, remain limited. Therefore, we first aimed to describe the distribution of NLR on admission and its trajectory in a cohort of patients hospitalized with acute HFpEF. We then aimed to determine whether NLR on admission as well as NLR trajectory would be complementary to the Get with the Guidelines Heart Failure (GWTG-HF) risk score for outcome prediction.

\section{Methods}

Using Stanford Translational Research Integrated Database Environment (STRIDE), ${ }^{11}$ we identified 3,847 adult patients with a diagnostic code of "HFpEF" (ICD-9 code 428.3) between January 2002 and December 2013, in whom CBC data were available on both admission and discharge. HFpEF was diagnosed clinically in the presence of an elevated NT-proBNP level $>300 \mathrm{pg} / \mathrm{mL}$ or evidence of heart failure with a LVEF $>50 \%$. Evidence of heart failure was based on the presence of pulmonary edema on chest $\mathrm{X}$-ray, peripheral edema with documented increased right atrial pressure on physical examination or echocardiography. 
Of these patients, 1,923 had an admission for acute HF. Among them, 1,343 patients were excluded due to the exclusion criteria (Figure 1). Complete blood count (CBC) data were not available on discharge day for 137 patients. Overall, 443 patients met the inclusion and exclusion criteria, and were included in the analysis (Figure 1). Patients' clinical data were curated using medical chart review by 2 physicians (KB and $\mathrm{FH}$ ), and included demographics (age, gender, race/ ethnicity), vital signs (heart rate, blood pressure, respiratory rate, oxygen saturation), anthropomorphic measures (height, weight, body mass index), co-morbidities including diabetes mellitus, systemic hypertension, chronic obstructive pulmonary disease, coronary artery disease, atrial fibrillation. Laboratory values on admission including $\mathrm{CBC}$ with differential, basic metabolic profile, NT-proBNP (Roche diagnostics, Mannheim, Germany) and medication list were recorded. The NLR is defined as the ratio of the neutrophil to the lymphocyte values. Trajectory are defined as absolute change of NLR calculated as $\left(\mathrm{NLR}_{\mathrm{dis}}-\mathrm{NLR}_{\mathrm{adm}}\right)$ or relative change of NLR calculated as $100 *\left(\mathrm{NLR}_{\mathrm{dis}}-\mathrm{NLR}_{\mathrm{adm}}\right) / \mathrm{NLR}_{\mathrm{adm}}$. We selected the first admission for HFpEF available in the chart with complete clinical data.

The GWTG-HF risk score was calculated according to the statistical model as per Peterson et al. ${ }^{12}$ The variables included in this score were age, black race, history of chronic obstructive pulmonary disease, heart rate, systolic blood pressure, blood urea nitrogen, and serum sodium. ${ }^{12,13}$

The primary outcome was all-cause mortality. The US Social Security Death Index was used to ascertain the mortality status of each patient as of February 2014 and the time of the event was determined from whichever was later. Accuracy of the status was confirmed using chart review and care everywhere network (Epic Systems Corporation, Verona WI).

Quantitative data are expressed as mean \pm standard deviation if normally distributed or median (interquartile range) if not. Normality of the data was tested using Kolmogorov-Smirnov test. Qualitative variables are presented as numbers and percentages. Correlations between continuous variables were expressed using Pearson's correlation

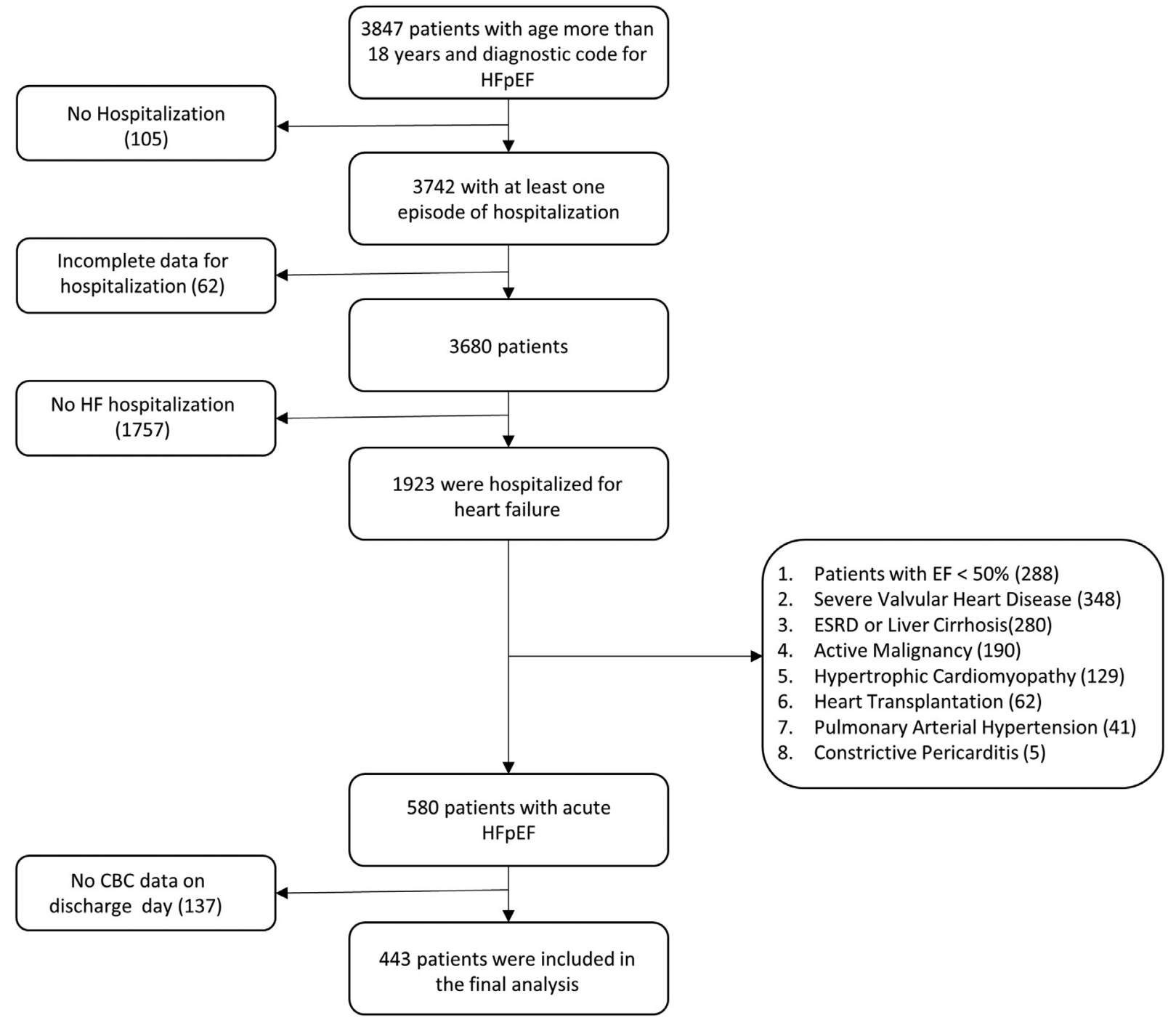

Figure 1. Study population flow chart. $\mathrm{CBC}=$ complete blood count $\mathrm{HFpEF}=$ heart failure with preserved ejection fraction; $\mathrm{HF}=$ heart failure; $\mathrm{EF}=$ ejection fraction; ESRD = end-stage renal disease. 
coefficients (r) and their p values and represented when appropriate using scatter plots. Correlates of all-cause mortality were assessed using univariable Cox proportional hazard analysis. Variables with $\mathrm{p}<0.20$ on univariable analysis were entered in multivariable stepwise Cox proportional hazard analysis using the available follow-up period. Our first step for outcome analysis was to analyze the outcome prediction ability of GWTG-HF risk score in our cohort. Our second step was to evaluate whether NLR on admission as well as absolute NLR trajectory would be incremental in predicting outcome in adjusted and unadjusted models and to assess whether they would be complementary to the GWTG-HF risk score. Hazard ratios and 95\% confidence interval (CI) of continuous variables are presented per standard deviation of the considered variable for comparison purposes. Model fit was tested using likelihood ratio test and chi-square analysis. Kaplan-Meier survival curves were compared using the log-rank test. We also evaluated whether adding NLR on admission or its trajectory to the GWTG-HF risk score improved the area under the operator-receiver curve (AUC) or the net reclassification (NRI) at 1,2 , and 3 years after admission. All $\mathrm{p}$ values $<0.05$ were considered statistically significant. Statistical analyses were performed using SPSS 22 (IBM Corporation, Armonk, NY), NCSS 11 (NCSS, Kaysville, UT), and SAS software, version 9.3 (SAS Institute, Cary, NC). Data visualizations were generated with "ggplot2" package in $\mathrm{R}$ (v.3.3.2).

\section{Results}

Clinical and biological characteristics on admission of the 443 patients included are presented in Tables 1 and 2. Mean age was $77 \pm 16$ years; $59 \%$ were women and the median duration of hospitalization was 5 ( 3 to 9 ) days. The GWTG-HF risk score was normally distributed as illustrated in Figure 2 and had a mean value of $41.4 \pm 8.3$. The median NT-proBNP, available in 271 patients $(58.8 \%)$, was $2,262(1,071$ to 5,243$) \mathrm{pg} / \mathrm{mL}$.

The NLR on admission was skewed to the right with a median value of 6.5 (3.6 to 11.1). The absolute NLR trajectory (defined as the absolute change in NLR at discharge and NLR on admission) was normally distributed with a mean value of $-2.0 \pm 11.2$, whereas the relative NLR trajectory was skewed to the left with a median value of $-23.6 \%$ ( -113.8 to 11.3 ). Figure 2 illustrates a violin plot of NLR on admission. A scatter plot depicting NLR on admission and absolute NLR trajectory showed that NLR on discharge was lower than that on admission for a majority of patients $(60.7 \%$; Figure 2$)$.

During a median follow-up of 2.2 (0.3 to 4.9$)$ years, 121 patients (27.3\%) died. As shown in Table 3, NLR at discharge (HR 1.25; 95\% CI 1.12 to $1.56 ; \mathrm{p}<0.001$ ) and NLR on admission (HR 1.18; 95\% CI 1.02 to $1.35 ; \mathrm{p}=0.02$ ) were significantly and absolute NLR trajectory (HR 1.18; $95 \%$ CI 0.99 to $1.42 ; \mathrm{p}=0.06$ ) tended to be associated with the outcome, whereas relative NLR trajectory was not $(\mathrm{p}=0.98)$. Using multivariable hierarchical modeling, NLR on admission (HR 1.18; 95\% CI 1.00 to 1.38 ), $\mathrm{p}=0.04$ ) and absolute NLR trajectory (HR 1.26; 95\% CI 1.10 to 1.45 ; $\mathrm{p}=0.001)$ were independently associated with outcome
Table 1

Clinical characteristics of the study population $(n=443)$

\begin{tabular}{lc}
\hline Clinical characteristics & \\
\hline Age (years) & $76.7 \pm 15.5$ \\
Women & $259(58.5 \%)$ \\
Body mass index $\left(\mathrm{kg} / \mathrm{m}^{2}\right)$ & $28.4 \pm 7.2$ \\
$\quad>25$ & $307(69.3 \%)$ \\
$<19$ & $16(3.6 \%)$ \\
19 to 25 & $120(27.1 \%)$ \\
White & $343(77.4 \%)$ \\
Black & $26(5.9 \%)$ \\
Other & $74(16.7 \%)$ \\
Hypertension & $428(96.6 \%)$ \\
Diabetes mellitus & $157(35.4 \%)$ \\
Coronary artery disease & $258(58.2 \%)$ \\
Peripheral vascular disease & $49(11.1 \%)$ \\
Chronic obstructive pulmonary disease & $138(31.2 \%)$ \\
Atrial fibrillation/flutter & $255(57.5 \%)$ \\
Left ventricular ejection fraction $(\%)$ & $58.4 \pm 4.8$ \\
Systolic blood pressure (mm Hg) & $134.4 \pm 25.3$ \\
Diastolic blood pressure (mm Hg) & $69.6 \pm 17$ \\
Heart rate (beats per min) & $84 \pm 20.4$ \\
Respiratory rate (breaths per min) & $20 \pm 4.4$ \\
Medication & \\
Angiotensin-converting enzyme & $188(42.4 \%)$ \\
$\quad$ inhibitor/angiotensin receptor blocker & \\
Beta-blocker & $254(57.3 \%)$ \\
Diuretics & $264(59.6 \%)$ \\
\hline
\end{tabular}

(Table 4) along with the GWTG-HF risk score. When considered in the subgroup of patients with NT-proBNP levels available $(\mathrm{n}=271)$, NLR on admission (HR $1.31 ; 95 \%$ CI 1.07 to $1.62 ; \mathrm{p}=0.008$ ) and absolute NLR trajectory (HR $1.39 ; 95 \%$ CI 1.12 to $1.55 ; \mathrm{p}<0.001$ ) were independently associated with outcome (Table 4) along with the GWTG-

Table 2

Vital signs and laboratory values for patient population $(n=443)$

\begin{tabular}{lc}
\hline White blood cell count $(* \mathrm{~K} / \mu \mathrm{L})$ & $10.8 \pm 5.8$ \\
Absolute neutrophil count $(* \mathrm{~K} / \mu \mathrm{L})$ & $4.9(7.3-10.1)$ \\
Absolute lymphocyte count $(* \mathrm{~K} / \mu \mathrm{L})$ & $1.1(0.7-1.6)$ \\
Neutrophil to lymphocyte & $6.5(3.6-11.1)$ \\
$\quad$ ratio on admission & \\
Neutrophil to lymphocyte & $4.7(3.0-8.5)$ \\
$\quad$ ratio at discharge & \\
Absolute NLR trajectory & $-2.0 \pm 11.2$ \\
$\quad$ discharge-admission) & \\
Relative NLR trajectory & $23.6(-113.8$ to 11.3$)$ \\
Hemoglobin $(\mathrm{g} / \mathrm{dL})$ & $11.8 \pm 2.1$ \\
Hematocrit $(\%)$ & $35.3 \pm 6.1$ \\
Mean corpuscular volume $(\mathrm{fL})$ & $91.4 \pm 7.3$ \\
Mean corpuscular hemoglobin & $33.5 \pm 1.0$ \\
$\quad$ concentration $(\mathrm{g} / \mathrm{dL})$ & \\
Red cell distribution width $(\%)$ & $15.5 \pm 2.4$ \\
Platelet count $(\mathrm{K} / \mu \mathrm{L})$ & $227.4 \pm 99.7$ \\
Serum creatinine $(\mathrm{mg} / \mathrm{dL})$ & $1.3 \pm 0.6$ \\
Blood urea nitrogen $(\mathrm{mg} / \mathrm{dL})$ & $27.2 \pm 18.8$ \\
Serum sodium $(\mathrm{mmol} / \mathrm{L})$ & $136.8 \pm 5.8$ \\
Serum potassium $(\mathrm{mmol} / \mathrm{L})$ & $4.2 \pm 0.7$ \\
N terminal pro-b type natriuretic & $2262(1071-5243)$ \\
peptide $(\mathrm{pg} / \mathrm{mL})(\mathrm{n}=271)$ & \\
\hline
\end{tabular}

Laboratory values stated are on admission (unless mentioned otherwise). 
(A)

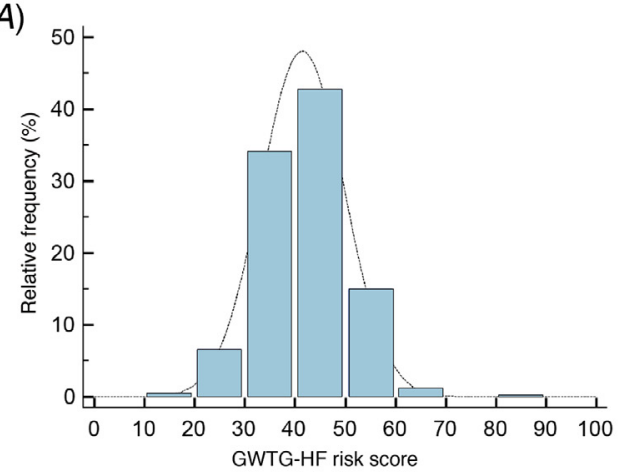

$(B)$

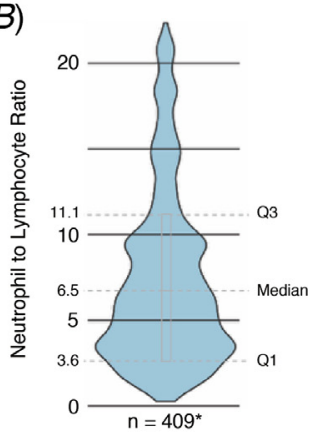

(C)

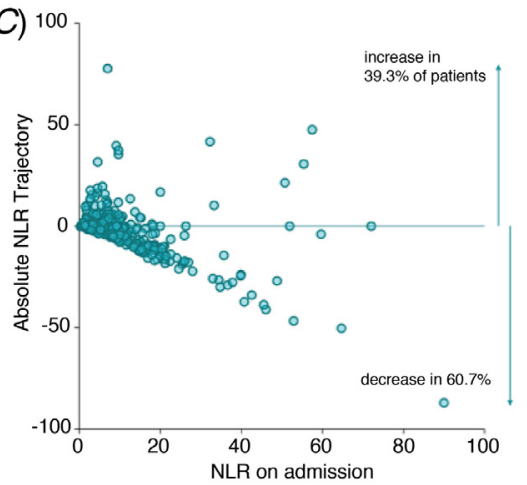

(D)
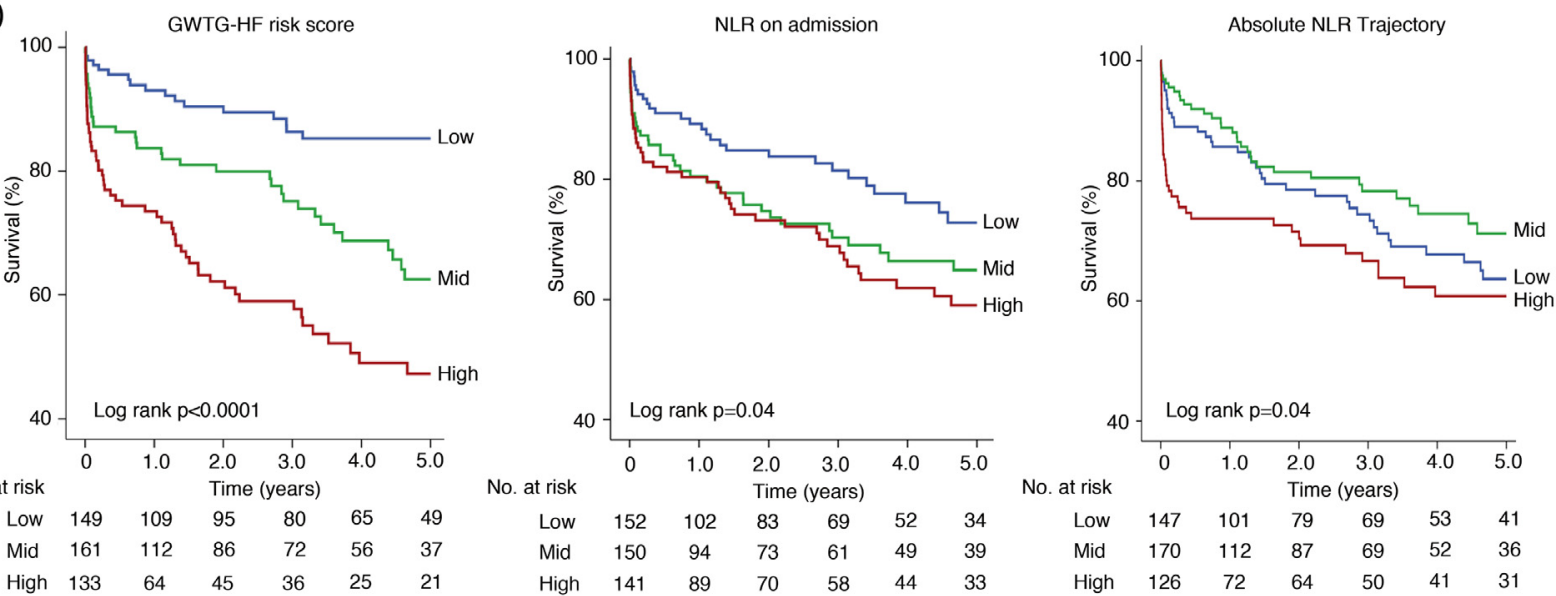

$(E)$

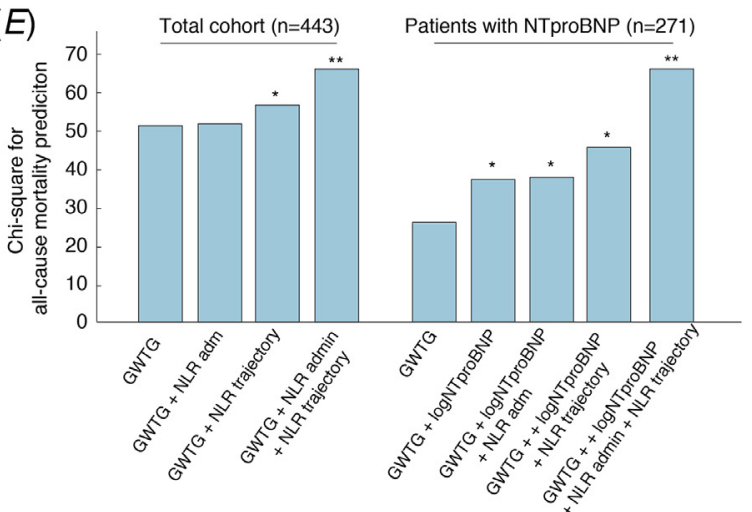

$(F)$

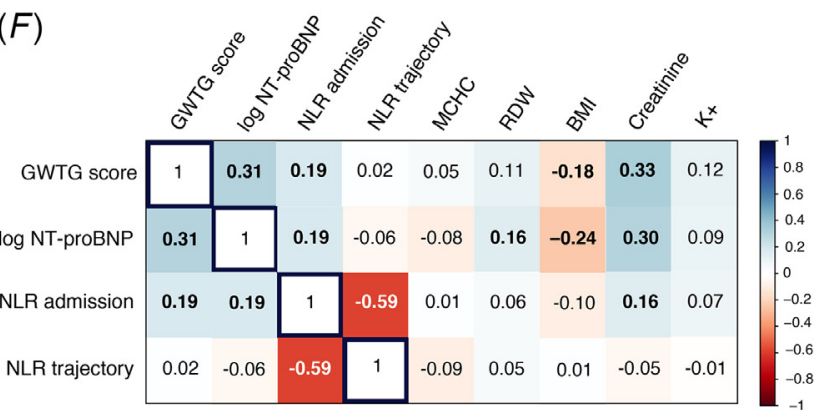

Figure 2. (A) Histogram of the Get With The Guidelines-Heart Failure (GWTG-HF) risk score following a normal distribution. (B) Violin plot of neutrophil to lymphocyte ratio on admission; $n=409$ on removing outliers. (C) Scatter plot of neutrophil to lymphocyte ratio (NLR) on admission and absolute NLR trajectory. (D) Kaplan-Meier survival curves according to tertiles of the GWTG-HF risk score; Kaplan-Meier survival curves according to tertiles of NLR on admission; Kaplan-Meier survival curves according to tertiles of absolute NLR trajectory. (E) Chi-square analysis for all-cause mortality prediction; *denotes $\mathrm{p}<0.05$ for comparison with the GWTG-HF risk score chi-square, and $* *$ denotes $\mathrm{p}<0.05$ for comparison with the NLR on admission chi-square and the NLR trajectory chi-square. (F) Correlation heatmap of the GWTG-HF risk score and other complementary metrics on admission, the NLR on admission and change after hospital discharge, for all patients with NT-proBNP available on admission $(n=271)$. Correlations are presented using Pearson's correlation coefficients and significant correlations (with $\mathrm{p}$ values $<0.05$ corrected for multiple analysis) are presented in bold. $\mathrm{BMI}=$ body mass index; $\mathrm{K}+=$ serum potassium level; $\mathrm{MCHC}=$ mean corpuscular hemoglobin concentration; NT-proBNP $=\mathrm{N}$-terminal pro B-type natriuretic peptide; RDW $=$ red blood cell distribution width.

HF risk score and NT-proBNP. Figure 2 illustrates the Kaplan-Meier survival curves according to tertiles for the GWTG-HF risk score, NLR on admission and absolute NLR trajectory. Patients with high tertiles of both GWTGHF risk score (log-rank $\mathrm{p}<0.001)$ and NLR on admission (Log-rank $p=0.04)$ as well as absolute NLR trajectory $(\log$-rank $\mathrm{p}=0.04)$ had worse outcome. Figure 2 shows the chi-square analysis for each model to predict outcome, the model improved the outcome prediction when absolute NLR trajectory ( $p<0.001$ ) was added to the GWTG-HF risk score, but not NLR on admission ( $\mathrm{p}<0.001)$. Adding both NLR on admission and absolute NLR trajectory significantly improved the outcome prediction model compared with the GWTG-HF risk score alone. In the 
Table 3

Univariable Cox proportional hazard analysis for all-cause mortality

\begin{tabular}{|c|c|c|}
\hline Correlates & $\begin{array}{l}\text { Standardized hazard } \\
\text { ratio }(95 \% \mathrm{CI})\end{array}$ & $\mathrm{p}$ Value \\
\hline Age (years) increase by $1 \mathrm{SD}$ & $1.84(1.36-2.13)$ & $<0.001$ \\
\hline Female & $1.09(0.76-1.56)$ & 0.64 \\
\hline Diabetes mellitus & $1.24(0.86-1.77)$ & 0.25 \\
\hline Coronary artery disease & $1.34(0.92-1.95)$ & 0.13 \\
\hline $\begin{array}{l}\text { Chronic obstructive pulmonary } \\
\text { disorder }\end{array}$ & $1.24(0.85-1.79)$ & 0.26 \\
\hline $\begin{array}{l}\text { Left ventricular ejection fraction } \\
(\%) \text { increase by } 1 \mathrm{SD}\end{array}$ & $1.10(0.78-1.28)$ & 0.48 \\
\hline $\begin{array}{l}\text { Systolic blood pressure decrease } \\
\text { by } 1 \mathrm{SD}\end{array}$ & $1.30(1.00-1.67)$ & 0.21 \\
\hline Heart rate increase by $1 \mathrm{SD}$ & $1.22(1.04-1.49)$ & 0.01 \\
\hline Respiratory rate increase by $1 \mathrm{SD}$ & $1.22(1.03-1.45)$ & 0.02 \\
\hline Body mass index decrease by $1 \mathrm{SD}$ & $1.25(1.07-1.56)$ & 0.03 \\
\hline $\begin{array}{l}\text { White blood cell count increase } \\
\text { by } 1 \text { SD }\end{array}$ & $1.06(0.89-1.19)$ & 0.67 \\
\hline Hemoglobin decrease by 1 SD & $1.16(1.04-1.37)$ & 0.12 \\
\hline Hematocrit decrease by $1 \mathrm{SD}$ & $1.20(1.02-1.47)$ & 0.08 \\
\hline $\begin{array}{l}\text { Mean corpuscular volume increase } \\
\text { by } 1 \mathrm{SD}\end{array}$ & $1.15(0.93-1.33)$ & 0.09 \\
\hline $\begin{array}{l}\text { Mean corpuscular hemoglobin } \\
\text { concentration decrease by } 1 \mathrm{SD}\end{array}$ & $1.29(1.08-1.54)$ & 0.004 \\
\hline $\begin{array}{l}\text { Red cell distribution width increase } \\
\text { by } 1 \text { SD }\end{array}$ & $1.34(1.20-1.54)$ & $<0.001$ \\
\hline Platelet count increase by $1 \mathrm{SD}$ & $1.00(0.82-1.22)$ & 0.51 \\
\hline Neutrophil count increase by $1 \mathrm{SD}$ & $1.10(0.90-1.28)$ & 0.25 \\
\hline $\begin{array}{l}\text { Lymphocyte count increase } \\
\text { by } 1 \mathrm{SD}\end{array}$ & $1.13(0.64-1.20)$ & 0.41 \\
\hline $\begin{array}{l}\text { NLR on admission increase } \\
\text { by } 1 \text { SD }\end{array}$ & $1.18(1.02-1.35)$ & 0.02 \\
\hline NLR at discharge increase by 1 SD & $1.25(1.12-1.56)$ & $<0.001$ \\
\hline $\begin{array}{l}\text { Absolute NLR trajectory increase } \\
\text { by } 1 \mathrm{SD}\end{array}$ & $1.18(0.99-1.42)$ & 0.06 \\
\hline $\begin{array}{l}\text { Relative NLR trajectory increase } \\
\text { by } 1 \text { SD }\end{array}$ & $1.00(0.81-1.24)$ & 0.98 \\
\hline Serum sodium increase by $1 \mathrm{SD}$ & $1.19(0.70-1.43)$ & 0.09 \\
\hline $\begin{array}{l}\text { Blood urea nitrogen increase } \\
\text { by } 1 \mathrm{SD}\end{array}$ & $1.56(1.35-1.81)$ & $<0.001$ \\
\hline Serum creatinine increase by $1 \mathrm{SD}$ & $1.33(1.17-1.50)$ & $<0.001$ \\
\hline Serum potassium increase by $1 \mathrm{SD}$ & $1.24(1.07-1.44)$ & 0.004 \\
\hline Blood glucose increase by $1 \mathrm{SD}$ & $1.05(0.90-1.22)$ & 0.48 \\
\hline Serum calcium increase by $1 \mathrm{SD}$ & $1.10(0.92-1.31)$ & 0.28 \\
\hline Log NTpro-BNP increase by 1 SD & $1.68(1.35-2.08)$ & $<0.001$ \\
\hline Length of stay increase by $1 \mathrm{SD}$ & $1.02(0.81-1.18)$ & 0.84 \\
\hline $\begin{array}{l}\text { GWTG-HF Risk Score increase by } \\
1 \text { SD }\end{array}$ & $1.89(1.62-2.37)$ & $<0.001$ \\
\hline
\end{tabular}

$\mathrm{SD}=$ standard deviation, NLR = neutrophil to lymphocyte ratio, NTproBNP $=\mathrm{N}$ terminal pro-B type natriuretic peptide, $\mathrm{GWTG}-\mathrm{HF}=\mathrm{Get}$ With The Guidelines - Heart Failure.

Hazard ratios normalized for SD.

subgroup of patients with NT-proBNP available $(\mathrm{n}=271)$, addition of both NLR on admission and absolute NLR trajectory increased the chi-square value of the model combining the GWTG-HF risk score and NT-proBNP. Furthermore, the addition of NLR on admission and absolute NLR trajectory to the GWTG-HF risk score substantially improved prediction of 1-year, 2-year, and 3-year mortality as seen by significant increases in AUC ( $\triangle$ AUC from +0.047 to $+0.023 ; \mathrm{p} \leq 0.047)$ and by significant improvements in net reclassification (NRI between 0.51 and $0.27 ; \mathrm{p} \leq 0.019$; Table 5). In our model, the optimal probability cutoff was $12.9 \%, 18.8 \%$, and $21.3 \%$ for prediction of 1-year, 2-year, and 3-year mortality, respectively. This translates into a $78.8 \%$ sensitivity and $60.5 \%$ specificity for prediction of 1-year mortality (Table 5).

A correlation heatmap (presented in Figure 2) shows that, on admission, high NLR was significantly but weakly correlated to high log NT-proBNP, high serum creatinine level, high GWTG-HF risk score, and low body mass index.

On multivariable Cox regression analysis focusing on biomarkers related with outcome among $\mathrm{CBC}$ parameters, higher RDW (HR 1.20; 95\% CI 1.07 to $1.37 ; \mathrm{p}=0.002$ ) and lower MCHC (HR 0.82; 95\% CI 0.68 to $0.99 ; \mathrm{p}=0.04$ ) were independently associated with all-cause mortality along with the GWTG-HF risk score (HR 1.90; 95\% CI 1.50 to $2.20 ; \mathrm{p}<0.001$ ), NLR on admission (HR $1.20 ; 95 \%$ CI 1.01 to $1.40 ; p=0.03$ ) and absolute NLR trajectory (HR $1.22 ; 95 \%$ CI 1.07 to $1.41 ; \mathrm{p}=0.003)$.

\section{Discussion}

The main finding of our study is that NLR on admission and absolute NLR trajectory are associated with all-cause mortality in patients with acute HFpEF beyond the wellvalidated GWTG-HF risk score.

The importance of the NLR in patients with cardiovascular disease was first recognized in patients with ischemic heart disease and myocardial infarction. ${ }^{14,15}$ Recently, the prognostic value of NLR in patients with heart failure has further been investigated; however, majority of the previously published studies were conducted in patients with HF-reduced EF. ${ }^{14,16-20}$ For example, Uthamalingam et al investigated 1,212 consecutive patients admitted with acute decompensated heart failure, showing the superior predictive ability of NLR for mortality than other CBC-related markers. ${ }^{21}$ In a large population-based longitudinal study of 5,301 African-American participants of the Jackson Heart Study, Kim et al have demonstrated that NLR was associated with all-cause mortality, coronary heart disease, and $\mathrm{HF}^{22}$ However, there have been limited data on NLR in exclusive HFpEF populations. Ours is one of the very few studies to establish the role of NLR for risk stratification for patients hospitalized with acute HFpEF.

The main original contribution of our study is to assess the value of NLR in well-curated and representative cohort of patients hospitalized for acute HFpEF. First, we have observed that the NLR decreased in majority of patients admitted with acute HFpEF and that this decrease relates to outcome. Consistent with previous studies, we have shown that NLR may carry more prognostic information than neutrophil or lymphocyte counts alone. One of the greatest contributions of this study is to demonstrate the incremental value of NLR on admission and absolute NLR trajectory to the GWTG-HF risk score for long-term outcome prediction in HFpEF. The GWTG-HF risk score has been widely used and validated in accordance with the American Heart Association GWTG-HF module to predict in-hospital mortality of patients hospitalized with HF with reduced or preserved ejection fraction. ${ }^{12,23,24}$ Furthermore, despite having been developed to predict in-hospital mortality, it is also 
Table 4

Multivariable Cox proportional hazard analysis to predict overall all-cause mortality with GWTG-HF risk score and NLR on admission in the model

\begin{tabular}{|c|c|c|c|c|}
\hline \multirow[t]{2}{*}{ Factors } & \multicolumn{2}{|c|}{ Entire cohort $(n=443)$} & \multicolumn{2}{|c|}{ Subgroup with NT-proBNP available $(\mathrm{n}=271)$} \\
\hline & Hazard ratio $(95 \% \mathrm{CI})$ & $\mathrm{p}$ Value & Hazard ratio $(95 \% \mathrm{CI})$ & $\mathrm{p}$ Value \\
\hline GWTG-HF risk score & $1.98(1.62-2.43)$ & $<0.001$ & $1.62(1.17-2.04)$ & $<0.001$ \\
\hline Absolute NLR trajectory & $1.26(1.10-1.45)$ & 0.001 & $1.39(1.12-1.55)$ & $<0.001$ \\
\hline $\log$ NT-proBNP & - & - & $1.50(1.20-1.88)$ & $<0.001$ \\
\hline
\end{tabular}

GWTG-HF = Get With The Guidelines - Heart Failure, NLR = neutrophil to lymphocyte ratio, NT-proBNP = N terminal pro-B type natriuretic peptide.

Variables included in the analysis were NLR on admission, absolute NLR trajectory (discharge - admission), GWTG-HF risk score and log NT-proBNP; hazard ratios normalized for standard deviation.

Table 5

Improvements in C-statistic and optimal predicted probability cutoff in prediction of all-cause mortality by addition of the NLR on admission and NLR trajectory to the GWTG-HF risk score

\begin{tabular}{|c|c|c|c|c|c|c|c|c|}
\hline \multirow[b]{2}{*}{$\begin{array}{l}\text { All-cause } \\
\text { mortality }\end{array}$} & \multicolumn{6}{|c|}{ C-statistic } & \multicolumn{2}{|c|}{ Net reclassification improvement } \\
\hline & $\begin{array}{c}\text { AUC for } \\
\text { GWTG-HF risk } \\
\text { score }(95 \% \mathrm{CI})\end{array}$ & $\begin{array}{c}\Delta \mathrm{AUC} \\
(95 \% \mathrm{CI})\end{array}$ & $\mathrm{p}$ Value & $\begin{array}{c}\text { Optimal } \\
\text { probability } \\
\text { cutoff }(\%)^{*}\end{array}$ & Sensitivity (\%) & Specificity (\%) & NRI $(95 \% \mathrm{CI})$ & $\mathrm{p}$ Value \\
\hline At 1-year FU & $\begin{array}{c}0.69 \\
\text { (0.62 to } 0.76)\end{array}$ & $\begin{array}{c}0.047 \\
\text { (0.013 to } 7.32)\end{array}$ & 0.0068 & 12.9 & 78.8 & 60.5 & $0.51(0.26$ to 0.76$)$ & 0.0001 \\
\hline At 2-year FU & $\begin{array}{c}0.70 \\
\text { (0.64 to } 0.76)\end{array}$ & $\begin{array}{c}0.022 \\
\text { (0.006 to } 0.044)\end{array}$ & 0.044 & 18.8 & 70.6 & 66.8 & $0.31(0.082$ to 0.54$)$ & 0.011 \\
\hline
\end{tabular}

AUC $=$ area under the operator-receiver curve; $\mathrm{FU}=$ follow-up; NLR = neutrophil to leukocyte ratio.

* The optimal predicted probability cutoff to predict all-cause mortality using the GTWG score, NLR at admission and its trajectory was defined as the probability threshold yielding the highest Youden index (=sensitivity + specificity-1). Sensitivity and specificity in the table represent the sensitivity and specificity when using this optimal cutoff.

predictive of long-term all-cause mortality in patients with acute $\mathrm{HFpEF}{ }^{23}$

Other CBC-based markers have also emerged as being associated with outcome in patients with HFpEF namely RDW and MCHC. ${ }^{25-28}$ RDW is automatically measured in a $\mathrm{CBC}$ and represents a variability of sizes of circulating erythrocytes. Horne BD et al previously showed that the CBC score was associated with cardiovascular mortality, whereas RDW was individually associated with allcause mortality among patients in the JUPITER trial. ${ }^{27}$ Relative hypochromia (reflected by low MCHC levels) has been shown to be independently associated with mortality in acute heart failure. ${ }^{28}$ Further studies will be needed to evaluate how NLR integrates with these other readily available CBC markers.

The present study should be interpreted in the context of its limitations. This study is retrospective single-center design; however, the cohort was well defined, representative of recent trials and registries and of moderately size which should give a degree of confidence in the reproducibility of the results. Additionally, we did not compare NLR with other inflammatory markers such as C-reactive protein or interleukin-6, because these parameters are not assessed routinely in our study population. In our study, the primary diagnosis was acute HFpEF. We have to recognize that NLR can also be elevated because of inflammatory conditions accompanying HFpEF. Finally, rehospitalization for HF was not assessed in this study as patients were followed at different institutions during the study period leading to incomplete data collection. In contrast to many other studies assessing NLR, however, our data assess dynamic changes of laboratory variables which will aid clinicians in management of patients with HFpEF.

In conclusion, NLR on admission and absolute NLR trajectory add prognostic information in patients hospitalized with acute HFpEF.

\section{Disclosures}

Dr. Horne is an inventor of complete blood count-based risk scores that Intermountain Healthcare has licensed to CareCentra, and is PI of research grants funded by Intermountain Healthcare's Foundry innovation program, the Intermountain Research and Medical Foundation, CareCentra, GlaxoSmithKline, and AstraZeneca for the development and/or clinical implementation of complete blood count-based clinical decision tools. We also would like to acknowledge the Srinivasan research fund.

\section{Acknowledgment}

This work was supported by the Intermountain-Stanford Collaboration Initiative and the Philips Royal Research Grant of Heart Failure with Preserved Ejection Fraction.

1. Steinberg BA, Zhao X, Heidenreich PA, Peterson ED, Bhatt DL, Cannon CP, Hernandez AF, Fonarow GC. Trends in patients hospitalized with heart failure and preserved left ventricular ejection 
fraction: prevalence, therapies, and outcomes. Circulation 2012;126: 65-75.

2. Bhatia RS, Tu J V, Lee DS, Austin PC, Fang J, Haouzi A, Gong Y, Liu PP. Outcome of heart failure with preserved ejection fraction in a population-based study. N Engl J Med 2006;355:260-269.

3. Chan MMY, Lam CSP. How do patients with heart failure with preserved ejection fraction die? Eur J Heart Fail 2013;15:604-613. Available at: http://dx.doi.org/10.1093/eurjhf/hft062.

4. Dhingra A, Garg A, Kaur S, Chopra S, Batra JS, Pandey A, Chaanine AH, Agarwal SK. Epidemiology of heart failure with preserved ejection fraction. Curr Heart Fail Rep 2014;11:354-365.

5. Ambrosy AP, Fonarow GC, Butler J, Chioncel O, Greene SJ, Vaduganathan M, Nodari S, Lam CSP, Sato N, Shah AN, Gheorghiade M. The global health and economic burden of hospitalizations for heart failure: lessons learned from hospitalized heart failure registries. $J \mathrm{Am}$ Coll Cardiol 2014;63:1123-1133.

6. Empel V van, H-P Brunner-La Rocca. Inflammation in HFpEF: key or circumstantial? Int J Cardiol 2015;189:259-263.

7. Tromp J, Khan MAF, Klip IjT, Meyer S, Boer RA de, Jaarsma T, Hillege H, Veldhuisen DJ van, van der Meer P, Voors AA. Biomarker profiles in heart failure patients with preserved and reduced ejection fraction. J Am Heart Assoc 2017;6:e03989.

8. Pearson TA, Mensah GA, Alexander RW, Anderson JL, Cannon RO 3rd, Criqui M, Fadl YY, Fortmann SP, Hong Y, Myers GL, Rifai N, Smith SCJ, Taubert K, Tracy RP, Vinicor F. Markers of inflammation and cardiovascular disease: application to clinical and public health practice: a statement for healthcare professionals from the centers for disease control and prevention and the American Heart Association. Circulation 2003;107:499-511.

9. Horne BD, Anderson JL, John JM, Weaver A, Bair TL, Jensen KR, Renlund DG, Muhlestein JB. Which white blood cell subtypes predict increased cardiovascular risk? J Am Coll Cardiol 2005;45: 1638-1643.

10. Silberman S, Abu-Yunis U, Tauber R, Shavit L, Grenader T, Fink D, Bitran D, Merin O. Neutrophil-lymphocyte ratio: prognostic impact in heart surgery. Early outcomes and late survival. Ann Thorac Surg 2018;105:581-586.

11. Lowe HJ, Ferris TA, Hernandez PM, Weber SC. STRIDE-an integrated standards-based translational research informatics platform. AMIA Аnпu Symp Proc 2009;2009:391-395.

12. Peterson PN, Rumsfeld JS, Liang L, Albert NM, Hernandez AF, Peterson ED, Fonarow GC, Masoudi FA. A validated risk score for in-hospital mortality in patients with heart failure from the American Heart Association get with the guidelines program. Circ Cardiovasc Qual Outcomes 2010;3:25-32.

13. Heidenreich PA, Hernandez AF, Yancy CW, Liang L, Peterson ED, Fonarow GC. Get with the guidelines program participation, process of care, and outcome for Medicare patients hospitalized with heart failure. Circ Cardiovasc Qual Outcomes 2012;5:37-43.

14. Wasilewski J, Pyka Ł, Hawranek M, Osadnik T, Kurek A, Skrzypek M, Niedziela J, Desperak P, Kułaczkowska Z, Brzezina M, Krawczyk M, Głsior M. Prognostic value of neutrophil-to-lymphocyte ratio in predicting long-term mortality in patients with ischemic and nonischemic heart failure. Pol Arch Med Wewn 2016;126:166-173.

15. Ghaffari S, Nadiri M, Pourafkari L, Sepehrvand N, Movasagpoor A, Rahmatvand N, Rezazadeh Saatloo M. Ahmadi M, Nader ND. The predictive value of total neutrophil count and neutrophil/lymphocyte ratio in predicting in-hospital mortality and complications after STEMI. J Cardiovasc Thorac Res 2014;6:35-41.

16. Benites-Zapata VA, Hernandez AV, Nagarajan V, Cauthen CA, Starling RC, Tang WHW. Usefulness of neutrophil-to-lymphocyte ratio in risk stratification of patients with advanced heart failure. Am J Cardiol 2015:115:57-61.

17. Turfan M, Erdogan E, Tasal A, Vatankulu MA, Jafarov P, Sonmez O, Ertas G, Bacaksiz A, Goktekin O. Neutrophil-to-lymphocyte ratio and in-hospital mortality in patients with acute heart failure. Clinics (Sao Paulo) 2014;69:190-193.

18. Wang X, Fan X, Ji S, Ma A, Wang T. Prognostic value of neutrophil to lymphocyte ratio in heart failure patients. Clin Chim Acta 2018;485: 44-49.

19. Huang W-M, Cheng H-M, Huang C-J, Guo C-Y, Lu D-Y, Lee CW, Hsu P-F, Yu W-C, Chen C-H, Sung S-H. Hemographic indices are associated with mortality in acute heart failure. Sci Rep 2017; $7: 17828$.

20. Tasal A, Erturk M, Uyarel H, Karakurt H, Bacaksiz A, Vatankulu MA, Turfan M, Sonmez O, Erdogan E, Ergelen M. Utility of the neutrophi to lymphocyte ratio for predicting in-hospital mortality after levosimendan infusion in patients with acute decompensated heart failure. J Cardiol 2014;63:418-423.

21. Uthamalingam S, Patvardhan EA, Subramanian S, Ahmed W, Martin W, Daley M, Capodilupo R. Utility of the neutrophil to lymphocyte ratio in predicting long-term outcomes in acute decompensated heart failure. Am J Cardiol 2011;107:433-438.

22. Kim S, Eliot M, Koestler DC, Wu W-C, Kelsey KT. Association of neutrophil-to-lymphocyte ratio with mortality and cardiovascular disease in the Jackson Heart Study and modification by the Duffy antigen variant. JAMA Cardiol 2018:3:455-462.

23. Boralkar KA, Kobayashi Y, Moneghetti KJ, Pargaonkar VS, Tuzovic M, Krishnan G, Wheeler MT, Banerjee D, Kuznetsova T, Horne BD, Knowlton KU, Heidenreich PA, Haddad F. Improving risk stratification in heart failure with preserved ejection fraction by combining two validated risk scores. Open Hear 2019;6:e00961. Available at: http:// openheart.bmj.com/content/6/1/e000961.abstract.

24. Smaha LA. The American Heart Association get with the guidelines program. Am Heart J 2004; 148:S46-S48.

25. Sotiropoulos K, Yerly P, Monney P, Garnier A, Regamey J, Hugli O, Martin D, Metrich M, Antonietti J-P, Hullin R. Red cell distribution width and mortality in acute heart failure patients with preserved and reduced ejection fraction. ESC Hear Fail 2016;3:198-204.

26. Felker GM, Allen LA, Pocock SJ, Shaw LK, McMurray JJ V, Pfeffer MA, Swedberg K, Wang D, Yusuf S, Michelson EL, Granger CB. Red cell distribution width as a novel prognostic marker in heart failure. Data from the CHARM program and the duke databank. J Am Coll Cardiol 2007:50:40-47.

27. Horne BD, Anderson JL, Muhlestein JB, Ridker PM, Paynter NP. Complete blood count risk score and its components, including RDW, are associated with mortality in the JUPITER trial. Eur J Prev Cardiol $2015 ; 22: 519-526$

28. Kleber M, Kozhuharov N, Sabti Z, Glatz B, Isenreich R, Wussler D, Nowak A, Twerenbold R, Badertscher P, Puelacher C, Fay de Lavallaz J du, Nestelberger T, Boeddinghaus J, Wildi K, Flores D, Walter J, Rentsch K, Eckardstein A von, Goudev A, Breidthardt T, Mueller C. Relative hypochromia and mortality in acute heart failure. Int J Cardiol 2019;286:104-110. 